\title{
Global monsoon and ocean drilling
}

\author{
Pinxian Wang ${ }^{1}$, Ryuji Tada ${ }^{2}$, and Steven Clemens ${ }^{3}$ \\ ${ }^{1}$ Laboratory of Marine Geology, Tongji University, Shanghai 200092, China \\ ${ }^{2}$ Department of Earth and Planetary Science, University of Tokyo, Tokyo 113-0033, Japan \\ ${ }^{3}$ Department of Geological Sciences, Brown University, Providence, RI 02912-1846, USA \\ Correspondence: Pinxian Wang (pxwang@tongji.edu.cn)
}

Received: 19 April 2018 - Revised: 21 July 2018 - Accepted: 30 July 2018 - Published: 22 October 2018

\begin{abstract}
The IODP-PAGES Workshop on Global Monsoon in Long-term Records was held on 7-9 September 2017, in Shanghai, China. Forty-eight scientists from 12 countries exchanged scientific findings from the seven recent IODP monsoon-related expeditions (see Table 1), discussed future research directions, and strongly recommended that monsoon system behavior be included in a future IODP initial science plan because it is one of the most active factors in the global climate system and crucially influences the global hydrological cycle.
\end{abstract}

\section{Paleo-monsoon in IODP}

Over the last 2 decades, there has been a dramatic increase in research activities and in the number of publications devoted to monsoon variability. Speleothem and ice-core records, together with deep-sea and terrestrial sediments, have enhanced the resolution of paleoclimate proxy records to an unprecedented level. In recent years (2013-2016), seven deepocean drilling expeditions were completed by IODP (Integrated Ocean Drilling Program and International Ocean Discovery Program) to explore the Cenozoic history of the Indian, East Asian and Australian monsoons (Fig. 1, Table 1). Earlier, between 1986 and 1999, at least 10 ODP (Ocean Drilling Program) cruises carried out drilling in African, American and Asian monsoon regions as well (Fig. 1, Table 2).

Traditionally, the variability of the monsoon has been studied almost exclusively on regional scales, by both the modern and paleo-monsoon communities. With the application of remote sensing and other new techniques over the last decade, the concept of the global monsoon has been introduced as a global-scale seasonal reversal of the three-dimensional monsoon circulation associated with the migration of rainfall in the monsoon trough and the intertropical convergence zone (ITCZ) (Trenberth et al., 2000; Wang and Ding, 2006). In an effort to understand better the dynamics of monsoon variability, the "Global Monsoon and Low-Latitude Processes:
Evolution and Variability" working group was established by PAGES (Past Global Changes) in 2007.

This working group conducted two successive symposia in 2008 and 2010 in Shanghai (Wang et al., 2009, 2012a), bringing together paleo and modern climatologists, as well as data producers and modelers. They compared monsoon studies from all regional monsoon systems and identified their similarities and differences across an exceptionally broad range of timescales, from interannual to tectonic, and tried to unravel the mechanisms causing variations in the global monsoon system and regional monsoon deviations from the global trend. As a result, a special issue with 13 contributions (Wang et al., 2012b) and two synthesis papers (Wang et al., 2014, 2017) were published. Obviously, the relevant community felt that the time was right for an international workshop to synthesize the research progress of monsoonrelated IODP and ODP expeditions from a new viewpoint of the global monsoon system.

\section{The IODP-PAGES Workshop}

After 2 years of preparation, the IODP-PAGES Global Monsoon Workshop took place on 7-9 September 2017, in Shanghai, co-sponsored by IODP, PAGES and IODP-China. Forty-eight scientists from 12 countries participated in the workshop, presented the scientific findings from the seven recent IODP monsoon-related expeditions (Table 1) as well as the previous ODP cruises (Table 2), discussed research 
Table 1. IODP monsoon expeditions.

\begin{tabular}{|c|c|c|c|c|}
\hline IODP & Topic & Dates & Drill Sites & References \\
\hline 346 & Sea of Japan, East China Sea: Asian monsoon & Jul-Sep 2013 & U1422-U1430 & Tada et al. (2015) \\
\hline 353 & Bay of Bengal: Indian monsoon rainfall & Nov 2014-Jan 2015 & U1443-U1448 & Clemens et al. (2016) \\
\hline 354 & Bengal Fan: Himalaya and climate & Jan-Mar 2015 & U1449-U1455 & France-Lanord et al. (2016) \\
\hline 355 & Arabian Sea: tectonic-monsoon interactions & Mar-May, 2015 & U1456-U1457 & Pandey et al. (2016) \\
\hline 356 & Indonesian Throughflow & Jul-Sep 2015 & U1458-U1464 & Gallagher et al. (2017) \\
\hline 359 & $\begin{array}{l}\text { Sea Level, Currents, and Monsoon Evolution } \\
\text { in the Indian Ocean }\end{array}$ & Sep-Nov 2015 & U1465-U1472 & Betzler et al. (2017); \\
\hline 363 & Western Pacific Warm Pool & Oct-Dec & U1482-U1490 & Rosenthal et al. (2017) \\
\hline
\end{tabular}

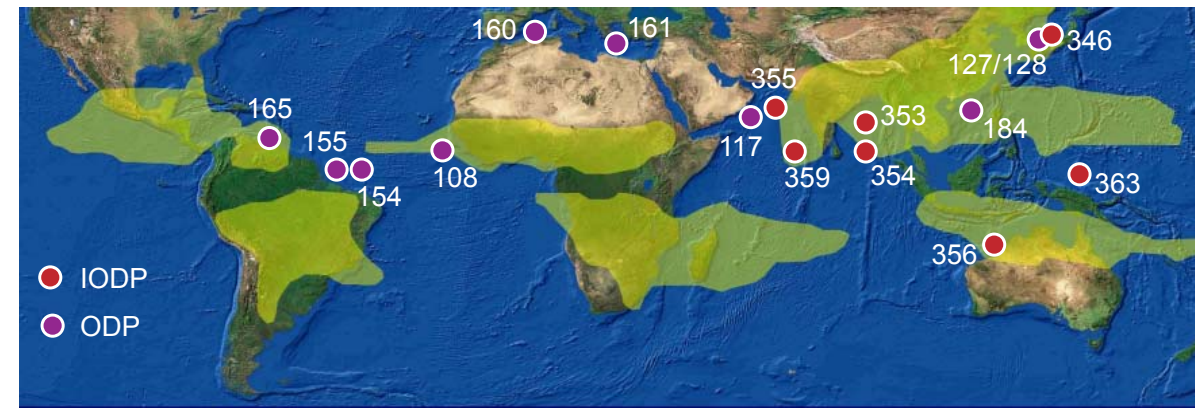

Figure 1. IODP/ODP monsoon expeditions.

directions, and made recommendations for the future IODP science program (Fig. 2).

The workshop started with presentations given by the PAGES Global Monsoon Working Group. On the basis of observation and proxy data, the working group found that the regional monsoons can vary coherently, although not perfectly, at various timescales. Monsoon variability may arise from external forcings or internal feedback processes within the climate system (Fig. 3). Within the global monsoon system, each subsystem has its own features, depending on its geographic and topographic conditions. Discrimination between global and regional components in the monsoon system is a key to revealing the driving factors in monsoon variations.

In the IODP Science Plan for 2013-2023, investigating the monsoon is listed in "Challenge 3", essentially as a factor controlling the regional patterns of precipitation (IODP, 2011). Accordingly, the recent monsoon-related IODP expeditions largely focused on the variations of the global hydrological cycle. For example, ocean drilling addressed this topic beginning $\sim 30$ years ago with ODP Leg 117 to the Arabian Sea, which established a regional paleo-monsoon history from monsoon wind-driven upwelling records. IODP Expedition 353 in 2014 targeted paleo-monsoon reconstruction based on salinity gradients induced by summer monsoon precipitation (Clemens et al., 2016). In the Sea of Japan during ODP Leg 127, a $0.9 \mathrm{Ma}$ sequence recovered 30 years ago was marked by alternation of dark and light layers in deep-water sediments, ascribed to millennial-scale variabil- ity of East Asian summer precipitation. In 2013, IODP Expedition 346 recovered a much longer monsoon record back to the middle Miocene at about $12 \mathrm{Ma}$ (Tada et al., 2015). In general, ODP-IODP drilling has yielded the longest highresolution records of regional monsoons, providing the basic data for a global synthesis of monsoon variations from tectonic, orbital, down to millennial timescales.

\section{Scientific recommendations}

A number of questions were discussed during the workshop, such as applicability of the global monsoon concept at geological timescales, monsoon response to external forcing and internal feedback, initiation of the current monsoon systems, the use and interpretation of monsoon proxies, and the role of monsoonal circulation in the global climate system. In order to promote the development of global monsoon research and to elucidate its role in the hydrological cycle at various geological timescales, the workshop came up with the following recommendations for future IODP activities to be incorporated into the IODP Science Plan beyond 2023.

\subsection{To include global monsoon in the future IODP science plan}

Monsoons have been included in the current IODP Science Plan, where "Challenge 3" reads as "What controls regional patterns of precipitation, such as those associated with monsoons or El Nino?" (IODP, 2011). Successive monsoon- 
Table 2. ODP monsoon expeditions.

\begin{tabular}{lclrc}
\hline Monsoon & Leg & Sea area & Drill sites & Year \\
\hline Northern African & 108 & Equatorial Atlantic & $657-668$ & 1986 \\
& 160 & Eastern Mediterranean & $963-973$ & 1995 \\
& 161 & Western Mediterranean & $974-979$ & 1995 \\
\hline South American & 154 & Ceara Rise & $925-929$ & 1994 \\
& 155 & Amazon Fan & $930-946$ & 1994 \\
& 165 & Caribbean Sea & 1002 & 1996 \\
\hline Asian & 117 & Oman margin & $720-731$ & 1987 \\
& $127 / 128$ & Sea of Japan & $794-799$ & 1989 \\
& 184 & South China Sea & $1143-1148$ & 1999
\end{tabular}

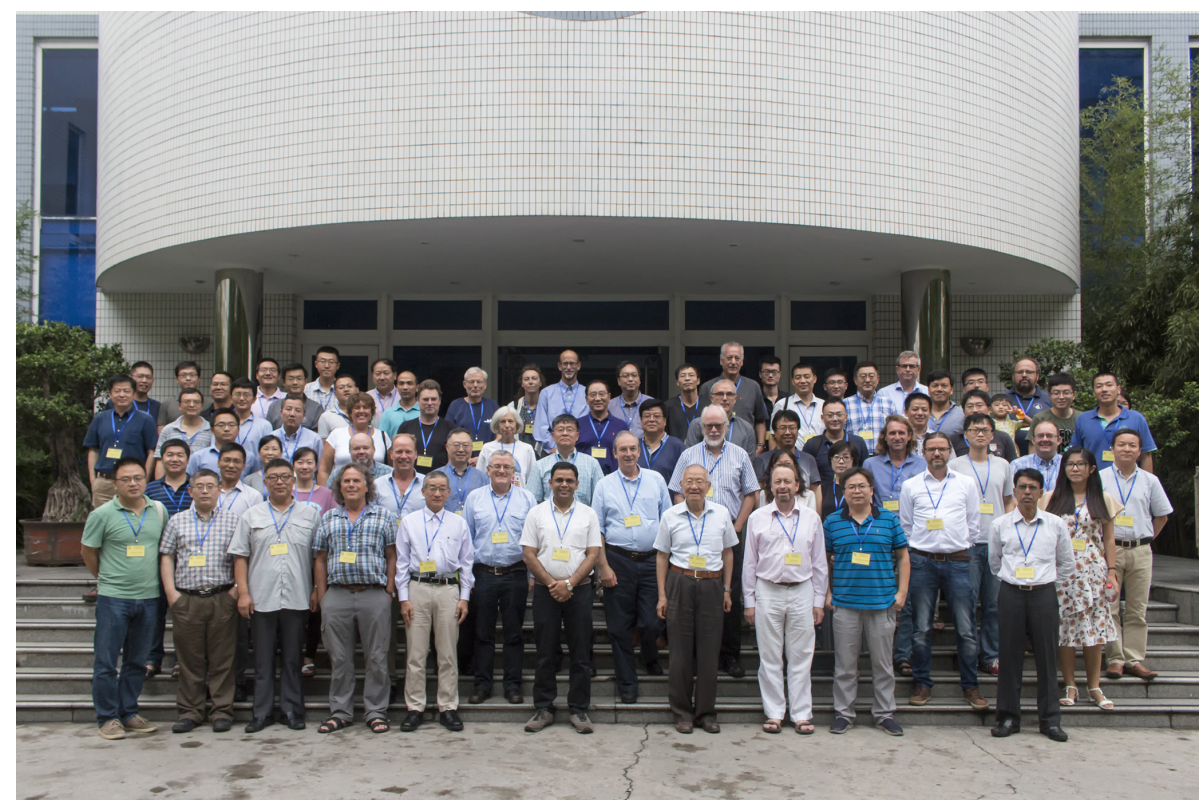

Figure 2. Participants of the IODP-PAGES Global Monsoon Workshop.

related expeditions in recent years provided an unprecedented opportunity to address these fundamental and societally critical questions, and overcome the challenge that the study of paleo-monsoons typically has been addressed or investigated as a regional supplement to the glacial cycles. Recent, transformational work, in contrast, emphasized the global nature of the monsoon system revealed by modern climatology and by recent findings in paleoclimatology. Although monsoon precipitation accounts for only $1 / 3$ of the modern global total rainfall, its spatial-temporal variation is the most mutable component in the global hydrological cycle, ranging from inter-annual to geological timescales. Together with ENSO and trade winds, the global monsoon comprises a major low-latitude component of the world climate system, and thus may provide a key to understanding the controlling factors of the hydrological cycle. Therefore, monsoon study should enter into the future IODP science plan as a global system with a strong influence on the global hydrological cycle.

\subsection{To recover deep-time monsoon records in high resolution}

Despite excellent progress in generating high-quality records over the past decade, the majority of high-resolution paleomonsoon records remain restricted to the late Quaternary, with only a limited number of sediment sequences at several IODP sites tracing back beyond the Pliocene. A much longer time coverage is urgently needed to reveal monsoon changes over the hot-house to ice-house transition in the Oligocene, and the tectonic background of when and how the modern monsoon systems were established. Some of these target sections could be accessed by deepening previously drilled ODP/IODP sites. These types of targets will provide information on the equilibrium response of monsoon sys- 


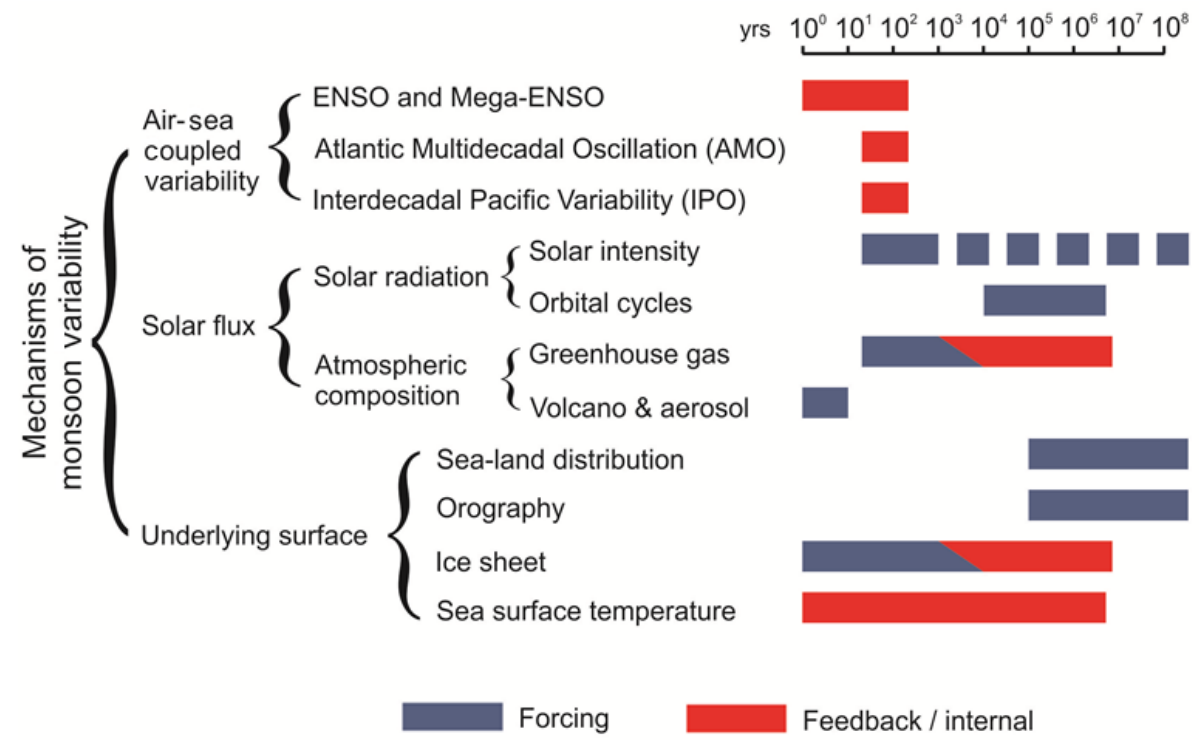

Figure 3. Mechanisms of global monsoon variability and their timescales (Wang et al., 2017).

tems to large-scale boundary conditions $\left(\mathrm{CO}_{2}\right.$ and global ice volume), fundamentally different from the rapidly evolving Plio-Pleistocene conditions.

\subsection{To develop and verify monsoon proxies}

A crucial issue is the accurate interpretation of monsoon proxies. Chemical and isotopic proxies have been extensively and successfully used in paleo-monsoon reconstructions, but opinions on their interpretation are divergent. The scientific debates call for further calibration of the current proxies and for development of new proxies, especially those indicative of the global monsoon as a climate system (see Wang et al., 2014, 2017, for a review). As many scientists working in monsoon regions tend to interpret all variance in the context of monsoon circulation, it is essential to discriminate the components of climate changes related to monsoon variability from those unrelated to monsoon variability. Progress requires integration across different disciplines working on the same monsoon questions from very different approaches, including geochemical, sedimentological and biological approaches.

\subsection{To extend geographic coverage of ocean drilling}

The existing deep-sea monsoon records are heavily biased to the Northern Hemisphere. High-resolution, pre-Quaternary records are urgently needed from the Southern Hemisphere, including monsoon areas off South America, Australia and South Africa. We expect that future targets of paleo-monsoon studies will continue to have a strong focus on margin environments, quite often located within exclusive economic zones. This will require enhanced focus on the part of IODP and its successors to initiate, develop, and nurture international relationships required to gain access to these regions. One possible solution is to find a way to extend the present IODP membership into developing countries without sharing the financial burden.

Data availability. No data sets were used in this article.

Competing interests. The authors declare that they have no conflict of interest.

Acknowledgements. Pinxian Wang acknowledges the support of NNSFC grant 91128000 and of the State Key Laboratory of Marine Geology, China.

Edited by: Will Sager

Reviewed by: three anonymous referees

\section{References}

Betzler, C., Eberli, G. P., Alvarez Zarikian, C. A., and the Expedition 359 Scientists: Proceedings of the International Ocean Discovery Program, 359, College Station, TX (International Ocean Discovery Program), https://doi.org/10.14379/iodp.pr.359.2016, 2017.

Clemens, S. C., Kuhnt, W., LeVay, L. J., and the Expedition 353 Scientists: Proceedings of the International Ocean Discovery Program, 353, College Station, TX (International Ocean Discovery Program), https://doi.org/10.14379/iodp.proc.353.2016, 2016.

France-Lanord, C., Spiess, V., Klaus, A., Schwenk, A. T., and the Expedition 354 Scientists: Proceedings of the 
International Ocean Discovery Program, 354, College Station, TX (International Ocean Discovery Program), https://doi.org/10.14379/iodp.proc.354.2016, 2016.

Gallagher, S. J., Fulthorpe, C. S., Bogus, K., and the Expedition 356 Scientists: Proceedings of the International Ocean Discovery Program, 356. College Station, TX (International Ocean Discovery Program), https://doi.org/10.14379/iodp.proc.356.2017, 2017.

IODP: Illuminating Earth's Past, Present, and Future, The Science Plan for the International Ocean Discovery Program 2013-2023, IODP: Integrated ocean drilling program, Washington, D.C., Integrated Ocean Drilling Program, 2011.

Pandey, D. K., Clift, P. D., Kulhanek, D. K., and the Expedition 355 Scientists: Proceedings of the International Ocean Discovery Program, 355, College Station, TX (International Ocean Discovery Program), https://doi.org/10.14379/iodp.proc.355.2016, 2016.

Rosenthal, Y., Holbourn, A. E., Kulhanek, D. K., and the Expedition 363 Scientists: Expedition 363 Preliminary Report: Western Pacific Warm Pool, International Ocean Discovery Program, https://doi.org/10.14379/iodp.pr.363.2017, 2017.

Tada, R., Murray, R. W., Alvarez Zarikian, C. A., and the Expedition 346 Scientists: Proceedings of the International Ocean Discovery Program, 346, College Station, TX (Integrated Ocean Drilling Program), https://doi.org/10.2204/iodp.proc.346.2015, 2015.
Trenberth, K. E., Stepaniak, D. P., and Caron, J. M.: The global monsoon as seen through the divergent atmospheric circulation, J. Climate, 13, 3969-3993, 2000.

Wang, B. and Ding, Q.: Changes in global monsoon precipitation over the past 56 years, Geophys. Res. Lett., 33, L06711, https://doi.org/10.1029/2005GL025347, 2006.

Wang, P., Wang, B., and Kiefer, T.: Global monsoon in observations, simulations and geological records, PAGES News, 17, 8283, 2009.

Wang, J., Emile-Geay, J., Guillot, D., Smerdon, J. E., and Rajaratnam, B.: Evaluating climate field reconstruction techniques using improved emulations of real-world conditions, Clim. Past, 10, 119, https://doi.org/10.5194/cp-10-1-2014, 2014.

Wang, P., Wang, B., and Kiefer, T.: Linking monsoon systems across timescales, PAGES News, 19, 86-87, 2012a.

Wang, P., Wang, B., and Kiefer, T.: Global monsoon across timescales, Clim. Dynam., 39, 1043-1044, 2012b.

Wang, P., Wang, B., Cheng, H., Fasullo, J., Guo, Z. J., Kiefer, T., and Liu, Z. Y.: The global monsoon across time scales: Mechanisms and outstanding issues, Earth-Sci. Rev., 173, 84-121, 2017. 